\title{
SCREENING FOR $\alpha$-AMYLASE IN CEREALS. IMPROVED GEL-DIFFUSION ASSAY USING A DYE-LABELLED STARCH SUBSTRATE
}

\author{
by \\ JØRN HEJGAARD \\ Department of Biochemistry and Nutrition, \\ Technical University of Denmark, DK-2800 Lyngby \\ and \\ GREGORY C. GIBBONS \\ Department of Biotechnology, Carlsberg Research Center, \\ Gamle Carlsberg Vej 10, DK·2500 Copenhagen. Valby
}

Keywords: Rapid $\alpha$-amylase test, barley, rye, wheat, triticale, blue-starch substrate

Radial diffusion into a gel slab containing dye-labelled starch as substrate provides a specific, reliable and rapid $\alpha$-amylase estimation of potential use in screening of a large number of cereal samples, including single grains or half-grains in early stages of a breeding program. The method has also been used to monitor $\alpha$-amylase activity in column chromatography eluates.

\section{INTRODUCTION}

Pre-harvest sprouting is a serious problem in rye, wheat and triticale, especially in the moist and temperate climate of North Western Europe. As well as producing shrivelled seeds, preharvest sprouting involves an activation and synthesis of the enzymes involved in starch breakdown and thus produces grains with partially modified storage carbohydrates. As these processes decrease baking quality, it has been a central breeding objective to produce varieties with greater resistance to sprouting in the ear. Due to the frequent correlation between high $\alpha$-amylase activity and pre-harvest sprouting there exists a need for a fast and simple $\alpha$ - amylase assay in breeding programmes. Furthermore, rapid $\alpha$-amylase determinations are useful in the milling, baking and brewing industries.

Radial diffusion into a substrate-containing gel slab is a rapid technique for the determination of enzymes, and several methods using either $\beta$ limit dextrin or starch as substrate for the assay of $\alpha$-amylase have been described $(2,4,6)$. As $\beta$ amylase supplements the action of $\alpha$-amylase both in the degradation of $\beta$-limit dextrin and starch, interference by $\beta$-amylase must be eliminated by heat-treatment of the sample extract before analysis (2). Several studies in recent years have shown that colorimetric measurement of the degradation of a commerci- 
ally available cross-linked dye-labelled starch substrate presents a specific and quantitative alternative to the direct and indirect $\alpha$-amylase methods normally used in cereal research $(1,3$, 5,11 ). The present study describes how dyelabelled starch can be used as substrate in a radial diffusion assay for $\alpha$-amylase activity in cereals.

\section{MATERIALS AND METHODS}

\subsection{Plant material}

Samples of rye flour covering a wide range of $\alpha$-amylase activities were obtained from Dr. A. TAllberg, The Swedish Seed Association, Svalöv. $\alpha$-Amylase activity of these samples had been determined by the method used routinely at Svalöv (9).

Seeds of hexaploid Triticale were obtained from Dr. U. Posselt, Landessaatzuchtanstalt, Universität Hohenheim, Stuttgart, West Germany.

\subsection{Extraction}

A single grain or half-grain was crushed using a pair of pliers, and extracted with $1.25 \mathrm{ml} 1 \%$ aqueous $\mathrm{NaCl}$ by vigorous shaking for 2 hours. After 20 min sedimentation, a 5 to $10 \mu$ aliquot of the supernatant liquid was analysed for $\alpha$ amylase activity. The same extraction procedure was used for $50 \mathrm{mg}$ flour samples, except that extracts were centrifuged for $10 \mathrm{~min}$ at $3000 \times$ $\mathrm{g}$ before analysis.

\subsection{Gel-diffusion assay}

$150 \mathrm{mg}$ agarose (type HSA, from Litex, Glostrup, Denmark) was dissolved in $15 \mathrm{ml}$ boiling 50 mm-phosphate buffer, $\mathrm{pH} 6.9$, containing $20 \mathrm{~mm}-\mathrm{CaCl}_{2}$, and $40 \mathrm{mg}$ blue-starch substrate (a gift from Pharmacia Norden $A B$, Uppsala, Sweden) was added. The substrate was uniformly suspended by vigorous stirring, and the gel quickly poured on to a levelled $10 \times 10$ $\mathrm{cm}$ glass plate hereby forming a uniform 1.5 $\mathrm{mm}$ gel layer. Following solidification of the gel ( $5 \mathrm{~min}$ ), wells (2. $5 \mathrm{~mm}$ in diameter for 5-7 $\mu \mathrm{l}$ samples or $3 \mathrm{~mm}$ for $10 \mu \mathrm{l}$ samples) were cut out with a gel puncher. Conveniently, 25 samples could be analysed on the same plate. If diffusion zones smaller than $15 \mathrm{~mm}$ in diameter were satisfactory, 50 samples were applied. Extracts were applied in the wells using Carlsberg constriction pipettes and the plate was incubated overnight at $25^{\circ} \mathrm{C}$ in a moist chamber. After incubation, the plate was immersed for $5 \mathrm{~min}$ in $5 \%$ acetic acid to stop the reaction, and subsequently washed for $5 \mathrm{~min}$ in distilled water. The washed plate was covered with a piece of filter paper and a $1.5 \mathrm{~cm}$ thick layer of cellulose tissue and subjected to a uniform pressure of about $10 \mathrm{~g} \cdot \mathrm{cm}^{-2}$ with a loaded glass plate for 15 min. In this way the gel was squeezed to $0.1 \mathrm{~mm}$ thickness, whilst the remaining enzyme and unbound dye were extracted into the absorbent material. After removal of the filter paper, the gel was dried onto the glass plate in a stream of hot air using a commercial hair dryer. The dried gel was stable and could be stored for later evaluation. Diameters of the transparent, circular zones were measured twice at right angles, and the mean value used for activity calculation, based on the assumption of a linear relationship between the diameter and the logarithm of enzyme activity (see section 3.).

The optimum $\mathrm{pH}$ for blue-starch breakdown in the gel-diffusion method was $\mathrm{pH}$ 6.5-7.0, which was comparable to the results found with the colorimetric Phadebas $\alpha$-Amylase Test (Pha:macia Norden AB, Uppsala, Sweden). It was possible for one person to extract and assay 250 samples per day. Normally the plates were incubated overnight at $25^{\circ} \mathrm{C}$, but the time of analysis could be reduced to about $2-4$ hours by incubation at elevated temperature $\left(45-50^{\circ} \mathrm{C}\right)$ near the optimum for the reaction $(3,11)$. The release of soluble dye could be followed visually, and it was easy to select an optimal incubation time. While the gel diffusion method uses the equivalent of one blue starch tablet per gel, the colorimetric method uses by definition one tablet per sample. This represents a saving of 24 tablets per 25 samples.

\section{RESULTS AND DISCUSSION}

Initial experiments were made with commercially available substrate-buffer tablets used in the colorimetric Phadebas Amylase Test. Due to the presence of tableting agents it was difficult to obtain a uniform distribution of blue-starch particles in the gel, and impossible to dry the 


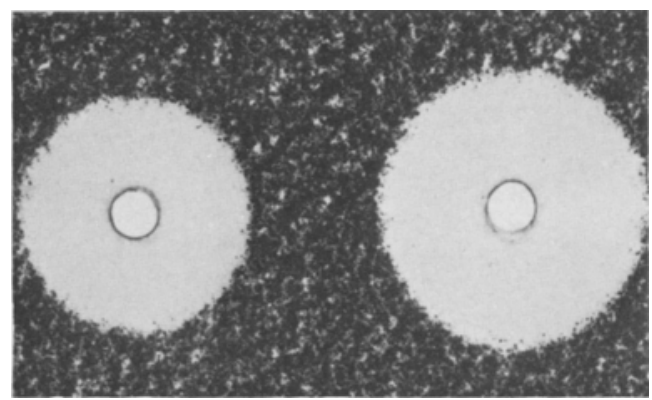

Figure 1. Appearance of diffusion zones after gel diffusion assay of $\alpha$-amylase. In this $2 \times$ enlarged photograph the granular nature of the blue-starch substrate is seen together with the sharp boundary between the circular clear zone and the residual substrate.

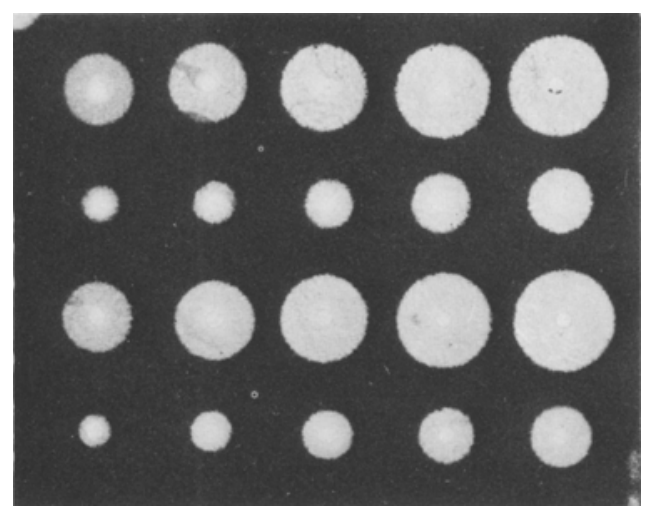

Figure 2. Standardisation of the blue-starch geldiffusion method. Top, serial dilution of a barley malt extract with water. From top right to bottom left, $10,9,8, \ldots 1$, arbitrary logarithmic units of $\alpha-$ amylase were applied. The slope of the resulting regression line was 1.11 (standard deviation \pm 0.02 ), and the correlation coefficient was 0.9988 . Bottom, identically made serial dilutions of the malt extract with an extract of ungerminated barley (Hiproly $x$ Mona5) (8). Slope of regression line: 1.16( \pm 0.02$)$. Correlation coefficient: 0.9989 .

developed gel to form an even film on the glass plate. These problems were overcome when the pure substrate powder was used. After fixing the plate with acetic acid, washing, pressing and drying, the diameter of the circular transparent zones could be measured accurately to $0.25 \mathrm{~mm}$ (Figure 1). With $\beta$-limit dextrin or starch as the substrate, transitional zones of about $1 \mathrm{~mm}$ width were observed between the unstained circular zones and the iodine-stained surroundings, and the accuracy to which the diameter could be measured was in the order of $0.5-1 \mathrm{~mm}$ $(2,7)$.

The reproducibility of the blue-starch method was tested by applying $5 \mu$ aliquots of a barley malt extract to 25 wells on the same plate. Following development, fixing and drying of the plate the mean diameter of the zone of hydrolysis was $14.31 \mathrm{~mm}$. The standard deviation was $\pm 0.18 \mathrm{~mm}$, corresponding to $1.3 \%$ at this diameter. When the same extract was analysed independently by another person, the mean diameter based on 5 determinations was $14.35 \pm 0.05 \mathrm{~mm}$. Standardisation of the geldiffusion method revealed a linear relationship between zone diameter and the logarithm of enzyme concentration (Figure 2).

It has been well established that blue-starch of the type used here is unaffected by $\beta$-amylase ( 1 , $5)$. In order to determine possible additive or inhibitory effects of $\beta$-amylase, or other components present in crude cereal extracts, on the present gel-diffusion method, barley malt extract was serially diluted with an extract of an

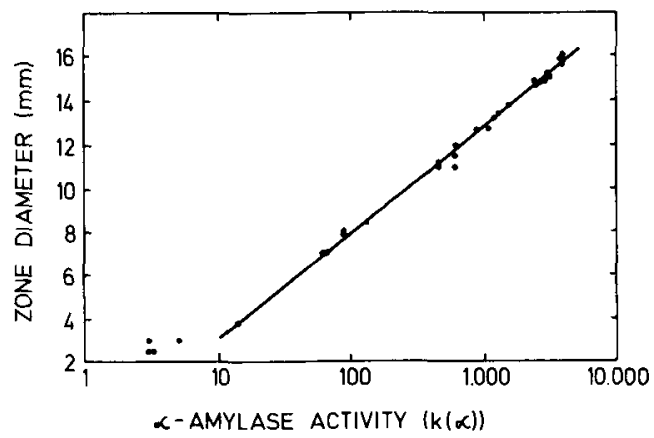

Figure 3. Comparison of $\alpha$-amylase activity in 30 rye samples, measured colorimetrically and by geldiffusion. The kinetics of breakdown of Zulkowskystarch, measured colorimetrically as starch-iodine complex, was used to determine the $\alpha$-amylase activity (9). Activity is expressed in standard $\mathrm{k}(\alpha)$ units on a logarithmic scale. For the gel-diffusion assay $5 \mu \mathrm{l}$ samples were applied in $2.5 \mathrm{~mm}$ wells (single determinations). Zone diameters smaller than $4 \mathrm{~mm}$ could not be measured accurately, and the four lowest values were not included in the regression analysis. Correlation coefficient: 0,993 . 


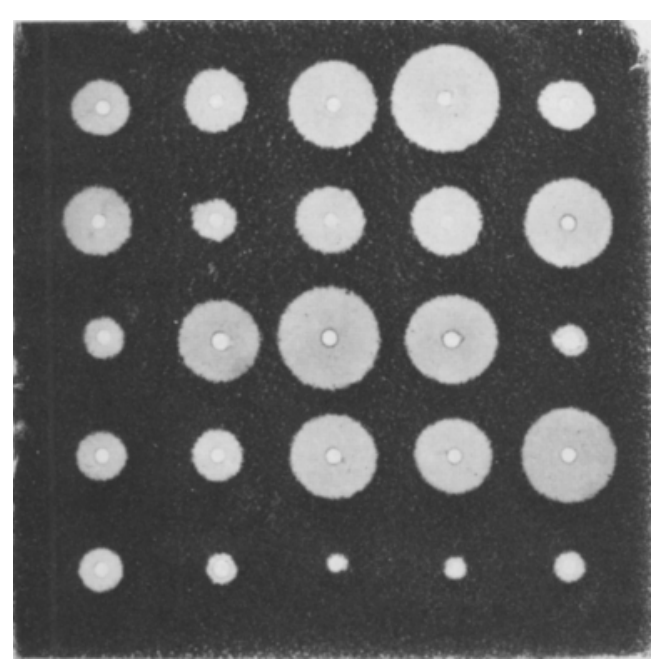

Figure 4. Screening for $\alpha$-amylase activity in 25 single grains of triticale. Five $\mu$ l extract (see 2.2) was applied in each $2.5 \mathrm{~mm}$ well.

ungerminated Hiproly barley line. This particular line has been shown to contain an exceptionally high level of $\beta$-amylase (8), and being ungerminated it was devoid of measurable $\alpha$ amylase activity. Gel-diffusion assay showed that addition of high- $\beta$-amylase barley extract did not increase the diameter of the diffusion zones (Figure 2). This result confirmed the specificity of the blue-starch substrate for $\alpha$-amylase. Statistical treatment of the results indicated, however, a slight inhibitory effect of the Hiproly extract. One possible explanation of this observation is a competitive inhibitory effect of endogenous substrate found in the ungerminated Hiproly material.

Analysis of 30 rye flour samples showed a high correlation between the zone diameter and the logarithm of the $\alpha$-amylase activity determined colorimetrically at Svalöv (Figure 3). The correlation was valid for 3 orders of magnitude of enzyme activity.

Analysis of single-grain extracts of triticale illustrated the variation in $\alpha$-amylase activity (7$6.000 \mathrm{k}(\alpha)$ units) observed while screening plant breeding material for preharvest sprouting (Figure 4).

The blue-starch gel-diffusion technique has also been used routinely in monitoring $\alpha$ - amylase activity in chromatography column eluates (Figure 5). The wide range of $\alpha$-amylase activity obtained in fractions from such a separation could be conveniently measured on the same $10 \times 10 \mathrm{~cm}$ plate without prior dilution or other treatment of the sample. For comparison, all fractions were analyzed by the colorimetric Phadebas tablet method. The results of the colorimetric Phadebas assay, where a sample of $1 \mu \mathrm{l}$ or $100 \mu \mathrm{l}$ was diluted with $4 \mathrm{ml}$ water, relevated that the activity ratio between fraction 16 and fraction 5 was greater than in the gel-diffusion method. In this experiment the major enzyme peak (fractions 15-21) was eluted with a high concentration of $\beta$-limit dextrin, a substrate for $\alpha$-amylase. Undoubtedly, the com-

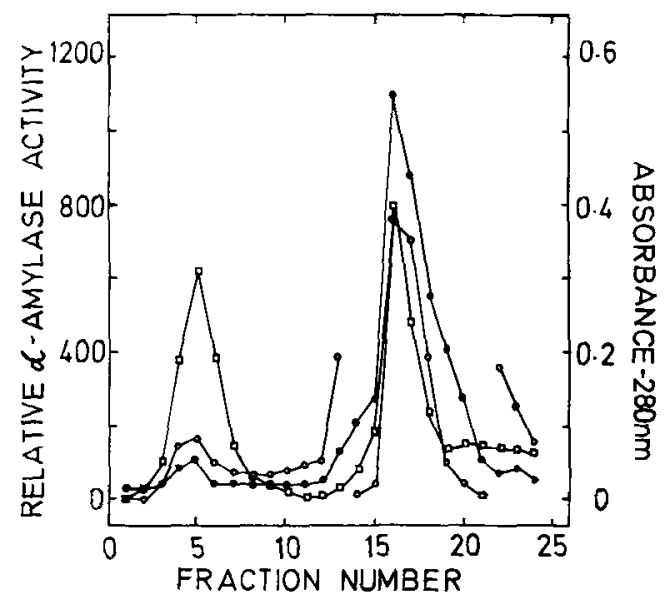

Figure 5. Determination of $\alpha$-amylase in fractions from affinity chromatography. Crude a-amylase was extracted from 7-day germinated barley (Hordeum vulgare, cv Nordal) and adsorbed to a $2.5 \times 7 \mathrm{~cm}$ column of $\beta$-cyclodextrin coupled to epoxy-activated sepharose 6B using the procedure of Silvanovich \& Hill. (10). After washing the column in $0.02 \mathrm{M}$ acetate buffer, $\mathrm{pH} 5.5$, containing $0.001 \mathrm{M}-\mathrm{CaCl}_{2}$, to remove contaminating protein (peak 1), $\alpha$-amylase was eluted with a solution of $\beta$-limit dextrin $(8$ $\mathrm{mg} \cdot \mathrm{ml}^{-1}$ ) in the same buffer (peak 2). $\square-\square$, Absorbance at $280 \mathrm{~nm}$; $-0, \alpha$-Amylase activity determined by gel-diffusion in blue-starch substrate. $10 \mathrm{ul}$ of each fraction was applied. $0-0, \alpha-$ Amylase activity determined colorimetrically. $100 \mu]$ samples (fractions $1-13$ and 22-24) or $1 \mu 1$ samples (fractions 14-2 I) were diluted into $4.0 \mathrm{ml} \mathrm{H} 2 \mathrm{O}$ and analysed with the standard Phadebas $\alpha$-Amylase Test. 
petitive effect of the $\beta$-limit dextrin substrate was effectively negated by the large excess of bluestarch substrate in the colorimetric method. This result illustrates the previously discussed (Figure 2) effects of other components present in samples to be analysed by the diffusion method.

The utility of the method is not restricted to cereal $\alpha$-amylase. It has also been used to localise peaks of $\alpha$-amylase activity in fractions from column chromatography of animal tissue extracts, and to determine $\alpha$-amylase inhibitors in cereals. For the latter experiments extracts of cereal grains were applied to blue-starch gels together with a standard amount of an $\alpha$-amylase of animal origin, and the reduction in size of the clear zone produced by the extract sample was used as a measure of the $\alpha$-amylase inhibitor content (L. Valentin Hansen and S. MeinHARDT-MøLLER, unpublished).

The major advantages of the method presented here are: 1) the assay is simple, inexpensive and well-suited for the screening of a large number of samples;2) no special equipment is needed, and the analyses can be made in a field laboratory; 3) $\alpha$-amylase activities differing by a factor of about $10^{3}$ can be determined on the same plate; 4) the determination is not affected by the presence of $\beta$-amylase; 5 ) the degradation of substrate can be followed visually during incubation; 6) well-defined transparent zones are obtained directly without staining; and 7) the dried plates are a permanent record of the experimental results.

\section{ACKNOWLEDGEMENTS}

The assistance of Ms. S. JENSEN and Mr. T. ScHmidT is gratefully acknowledged.

\section{REFERENCES}

1. Barnes, W. C. \& A. B. Blakfney: Determination of cereal alpha amylase using a commercially available dye-labelled substrate. Die Starke 26, 193-197 (1974)

2. Briggs, D. E.: Gel-diffusion method for the assay of $\alpha$-amylase. J. Inst. Brew. 68, 27-32 (1962)

3. Drews, E., B. FretzdorfF \& H.-D. OCKer: Bestimmung der alpha-Amylase-Aktivität im Roggenschrot mit dem Phadebas-alpha-Amylase-test. Getreide, Mehl u. Brot 30, 320-323 (1976)

4. Fossum, K. \& J. R. Whitaker: Simple method for detecting amylase inhibitors in biological materials. J. Nutrition 104, 930-936 (1974)

5. Fuller, P.: Rapid sorting test for $\alpha$-amylase activity in home grown wheat. Milling 154, 29$30(1972)$

6. Gothard, P. G.: A simple gel-diffusion assay of $\alpha$-amylase in ungerminated wheat grains. J. Sci. Fd. Agric. 27, 691-694 (1976)

7. Hayter, A. M. \& M. J. Aul.ison: A gel diffusion assay for diastatic activity, and its use in plant breeding. J. Inst. Brew. 78, 310-313 (1972)

8. Hejgaard, J., B. Køie, K.-E. Karisson \& A. TAILBERG: $\beta$-Amylase activity - a simple screening test in Hiproly barley breeding. Hereditas 90 , 145-147 (1979)

9. Otered, R. \& G. Jönsson: Electrophoretic studies of $\alpha$-amylase in wheat. II. J. Sci. Fd. Agric. 21, 385-392 (1970)

10. Sillvanovich, M. P. \& R. D. Hill: Affinity chromatography of cereal $\alpha$-amylase. Anal. Biochem. 73, 430-433 (1976)

11. Striner, K.: $\alpha$-Amylase-Test mit Phadebas. Schweiz. Brauerei-Rdsch. 87, 171-174 (1976) 